\title{
Innovative Technologies for the Public Administration Transformation
}

\author{
VALERIY DOVHAN ${ }^{1}$, NATALIIA HRUSHCHYNSKA ${ }^{2}$, OLHA KUDRINA*3, VICTORIA BOZHKOVA ${ }^{4}$, \\ TETIANA ZAPOROZHETS ${ }^{5}$, MAKSYM MAKARENKO ${ }^{6}$ \\ ${ }^{1}$ Scientific-Research Institute, NATIONAL ACADEMY OF THE STATE BORDER GUARD SERVICE OF UKRAINE \\ NAMED AFTER BOHDAN KHMELNYTSKYI, UKRAINE. \\ ${ }^{2}$ Public Administration Department, NATIONAL AVIATION UNIVERSITY, UKRAINE. \\ 3,4Business Economics and Administration Department, SUMY STATE MAKARENKO PEDAGOGICAL UNIVERSITY, \\ UKRAINE. *E-mail: olha.kudrina@gmail.com \\ ${ }^{5}$ Information Policy and Digital Technologies Department, NATIONAL ACADEMY OF PUBLIC ADMINISTRATION \\ UNDER THE PRESIDENT OF UKRAINE, UKRAINE. \\ ${ }^{6}$ ISTOMATOLOG FAMILY DENTISTRY CENTER, MM-DENTAL CLINIC, UKRAINE.
}

\begin{abstract}
The purpose of this article is to analyze the processes of transformation of public administration systems through the use of innovative technologies to meet the needs of modern society and reduce the monopoly on management by the state authorities. From the standpoint of the inevitable impact dictated by current socioeconomic conditions, the transformation processes are analyzed from the standpoint of economic expediency. The issues of the impact of innovative processes in the field of information technology on the traditional processes of public administration are considered. The prerequisites leading to the need for public administration transformation are described, and the main concepts and directions of this transformation are indicated.

As a proposed innovative transformation technology, tools for digitalization of public administration are described, aimed at improving the quality of services provided, harmonizing relationships between public administration entities, as well as aimed at optimizing and redistributing powers from state to municipal authorities.
\end{abstract}

Keywords: ID passport, Innovative Technologies, Transformation, Public Administration.

JEL Classification: M10, M15, H83 


\section{Introduction.}

Speaking about the transformation affecting public administration, it is worth noting that there are different interpretations of the very concept of public administration, which is why, first of all, it should be determined with the basic definition of this term.

The following definition most fully characterizes the concept of public administration: an integral systemic mechanism, the subsystems and elements of which are state, non-governmental and private structures and management institutions, the purpose of which is to satisfy the interests of society and ensure the solution of joint problems (Shavkun \& Dybchynska, 2017; Buha, 2021). By its nature, public administration combines mechanisms for improving internal coordination, management of human, financial and material resources, as well as communication and information systems.

The formation of public administration's very idea is based on the principles and values of a democratic society; its implementation indicated the direction of strengthening the processes of cooperation between the government and society, which gave rise to a synergistic effect of meeting the needs of stakeholders (Baklanova et al., 2020; Chernykh, 2020).

The catalyzing factor for the need to transform public administration is the technological and socio-economic transformations of modern society, which determine the need to increase the level of efficiency of public administration structures and the significantly increasing role of business entities requiring more effective ways of interacting with government bodies.

Despite the seeming economic evidence, it is worth noting that any processes of transformation of public administration invariably affect all aspects of modern society. By exerting a point effect on the seemingly long-studied processes, it is possible to obtain results that are fundamentally different from the original hypotheses. As the flagship of modern economic progress, information technologies can act both as a driver and as a stopper of the transformation process (Hidirova, 2020). Detailed analysis and study of such a complex process as the transformation of public administration is impossible without a comprehensive study of the key features that serve as its basis.

The processes of transformation of management systems have recently been accompanied by cardinal approaches to overseeing the public administration system's key positions (Kuzmenko et al., 2019). The search for new approaches to the organization of the public administration system led to the abandonment of the traditional type of centralized managerial innovation to the comprehensive involvement of the processes of self-organization and self-government of social systems and increasing the social efficiency of public administration.

Modern concepts of public administration and leadership focus on the high performance of public administration, political diversity in the decision-making process, the delegation of powers to the lower levels of the management hierarchy, more balanced distribution of power, responsibility and accountability, development and expansion of civic participation.

\section{Methodology.}

\subsection{Key principles of public administration and prerequisites for the use of instruments of influence}

The history of the formation and development of the public administration system's principles can be correlated with the nature of the formation of principles and scientific theories for the implementation of public administration and the application of key management theories in managing economic processes in various territorial units. Considering the model of the evolution of the very concept of public administration, it is easy to identify several key stages with their characteristic features, which are presented in fig. 1 for clarity. 
Fig.1. Stages of the evolution of the concept of public administration

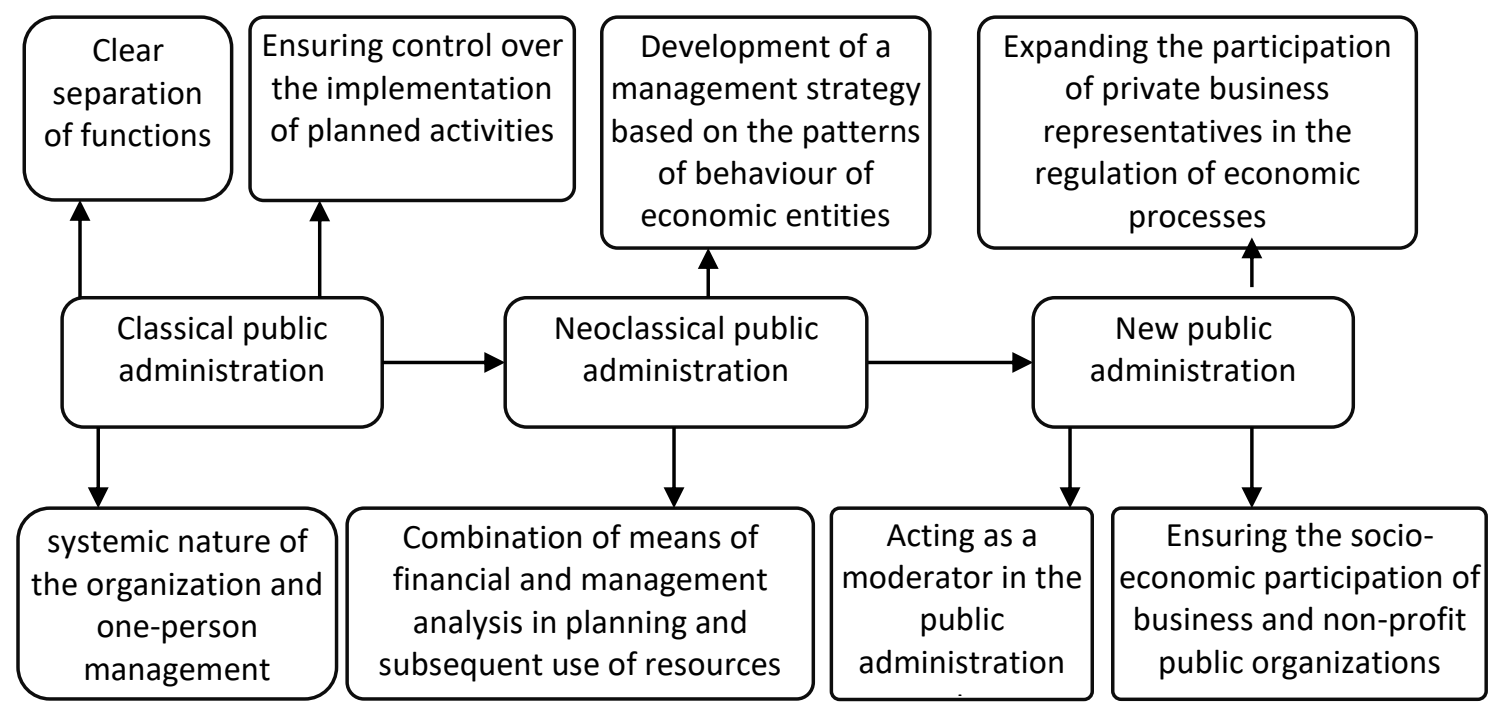

The use of innovative technologies for the transformation of public administration is basically based on the concept of the opposition between the desire for stability of the public administration system and the need for its constant critical rethinking, which entails updating the vector of movement along the path of modernizing the administrative apparatus and developing more effective methods of management activity.

The application of the approaches used in the business environment for the transformation of public administration can be carried out using the principle of identity of functions and tasks of the very concept of management as an economical category (Adejare et al., 2014; Thapa, 2020). Borrowing for the reform of public administration, in particular, the following principles and tools can be used:

- Decision making - in the business sector, the trend towards quick decision making is a key need to adapt to changing economic conditions. On the other hand, in government decision-making institutions, the time spent on the analysis, coordination of the correction can lead to a forced decision to adopt concomitant consequences. Borrowing flexibility in decision making is a way to move away from the traditional form of bureaucratization of management processes.

- Feedback - achieving effective results in a business environment is impossible without receiving and analyzing feedback at all levels of management impact. The wishes of customers and business partners are taken into account both in forming a development strategy and ensuring current operational activities. In turn, public administration, possessing a monopoly both in providing several services and in the formation of regulatory instructions, is not inclined to ensure the adjustment of its decisions, which potentially leads to reduced efficiency and quality of work.

- Encouraged initiative - business personnel are actively stimulated to develop creativity, increase efficiency, and stimulate innovation; this is a familiar approach to human capital management in the business environment, bearing fruit and proven to be effective. In contrast to this, state structures form a personnel policy based on strict adherence to the regulations and ensuring the fulfilment of planned indicators, the incentive system for effective work is often greatly distorted, and from an incentive, the function turns into a function of compensation for a lower level of wages, which naturally entails a loss of the target purpose of the system motivation.

Transformation technologies applied to focus on these principles will give a generally greater effect than similar attempts to modernize the state administration (Petrenko, 2011; Werehlst \& Istislam, 2018). It should be noted that modern realities dictate the need to form and develop qualitatively new forms of obtaining, analyzing, moving, and using information resources as one of the key means of systemic economic development (Andriyash \& Yevtushenko, 2018). Orientation of the use of transformation tools, with an emphasis on improving the use of information technologies, 
can contribute to a radical increase in the effectiveness of the partnership between public administration structures and the business community. The interconnection system of individual structures of public administration and the role of information technologies is presented in Fig. 2.

Fig. 2. Information system of public administration authorities

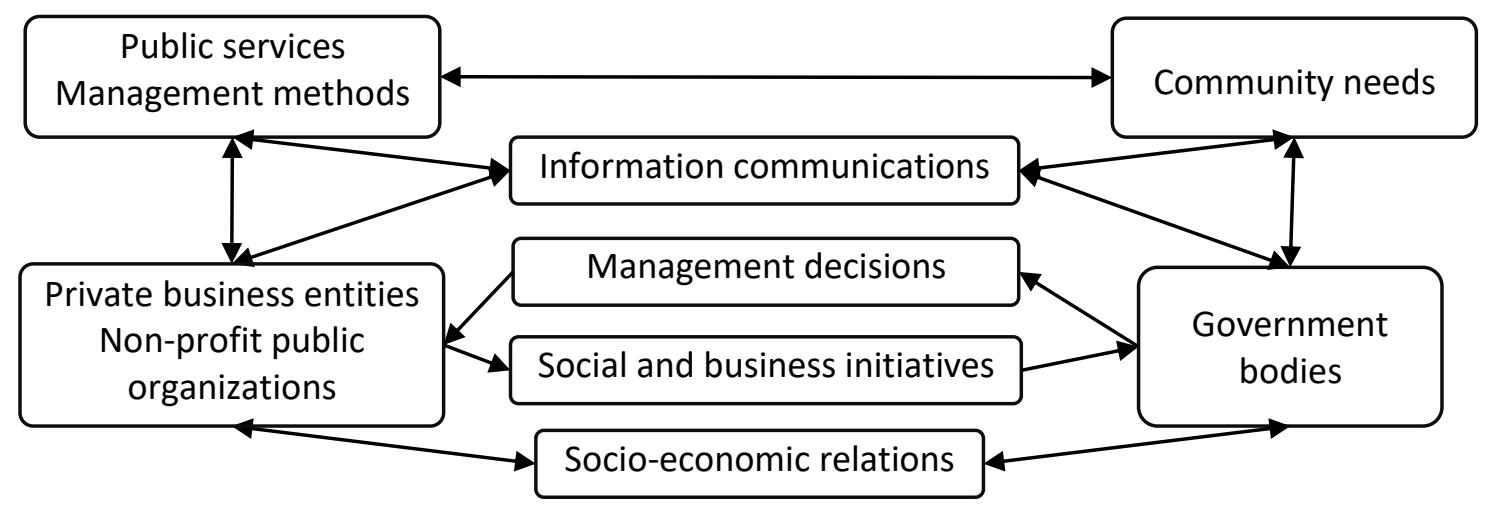

The processes of transformation of public administration, using innovative tools, are based on optimizing the relationship between government bodies and business entities while taking into account the need to comply with several conditions:

1) transformation from regulatory management to effective management, based not on compliance with regulatory procedures, but a transparent and clear system of performance targets and compliance with common standards;

2) increasing the efficiency of budget spending on information and technological modernization in the structure of interaction between public administration entities;

3) decentralization of management functions, based on the transfer of several powers of state authorities from their central level to regional structures of state administration;

4) improving the quality and efficiency of the provision of services to citizens, through the development and implementation of a system of electronic services, with the subsequent development of means to support electronic digital communication of state structures;

5) development of information technologies, allowing to improve the quality of use, storage and systematization of information resources in public administration structures.

The implementation of the processes of transformation and strengthening of the digitalization of public administration, first of all, requires an improvement in the system of providing administrative services aimed at improving the interaction of government bodies and civil society, namely, ensuring comfortable conditions for the extensive use of state information, ensuring free access to it for citizens, increasing the efficiency of the bodies public administration, and of course the creation of conditions in which citizens can take part in management processes aimed at improving public administration (; Kwilinski et al., 2019; Razumei \& Razumei, 2020).

A step-by-step approach to transforming and achieving tangible results from the digitalization process is schematically shown in Fig. 3. 
Fig. 3 Stages of transformation of public administration using innovative technologies

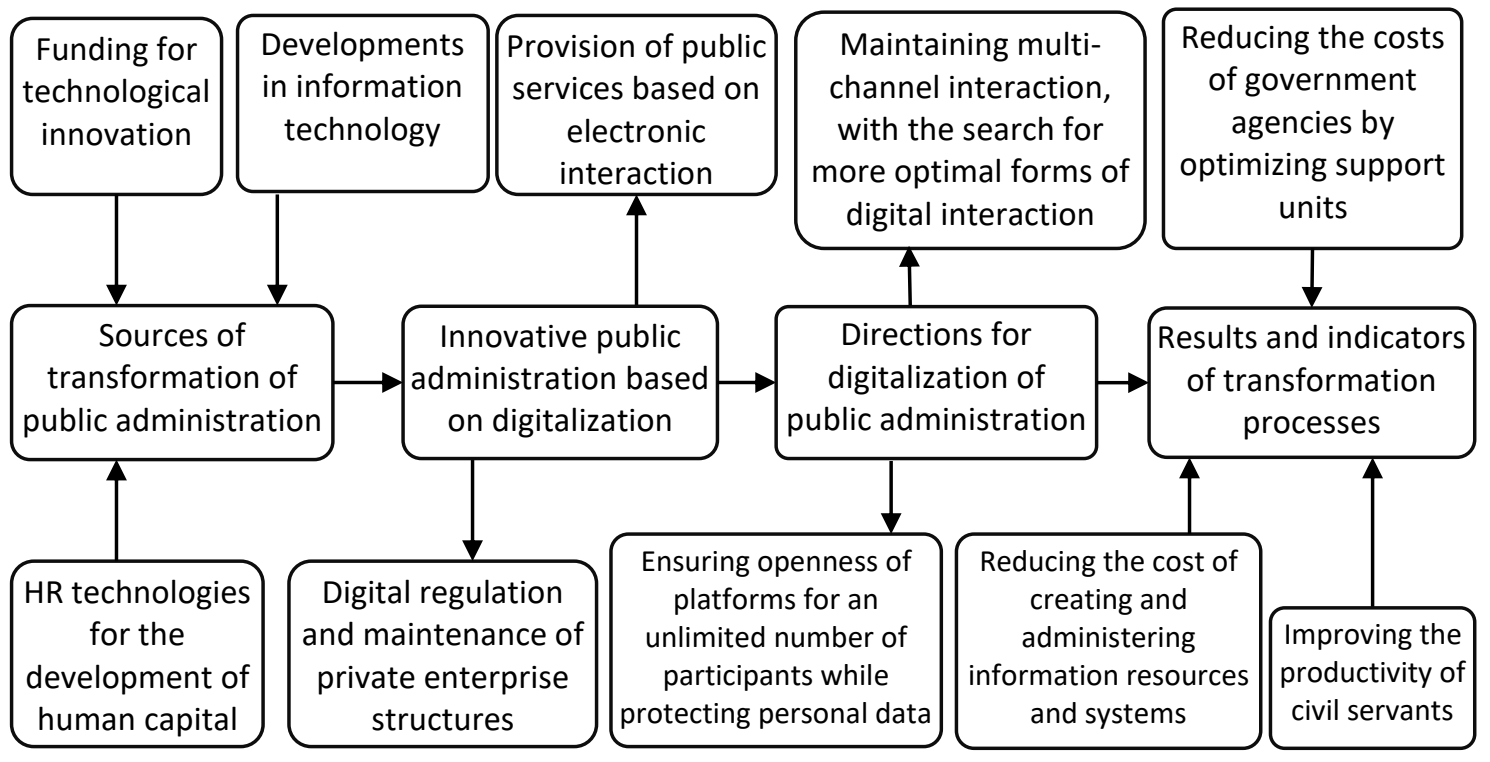

The introduction of information technologies for the transformation of public administration, particularly the system of providing administrative services, will increase the state administration's efficiency and serve as one of the universal tools for stabilizing social institutions.

The concept of transformation of public administration should serve the purpose of both increasing the efficiency of the functioning of the system itself and the indirect process of the inevitable decentralization of the monopoly of public administration. The government's main task is to provide local communities with the opportunity to independently solve their problems and control the quality of public services provided. This approach correlates with the basic values of local selfgovernment, democratization of society, and increasing the bureaucratic apparatus's efficiency.

\subsection{Digitalization of public administration as an innovative basis for systemic transformation.}

As mentioned above, the key imperative of the transformation of public administration is the use of innovative technologies to improve information and communication technologies to improve the quality and efficiency of the provision of public services and strengthen the processes of digitalization of the public administration system.

The digitalization system, using information technology, is an integrated approach to transforming traditional systems of functioning and implementation of public administration functions. The nature of the development and implementation of this system is aimed at improving the provision of administrative services, strengthening the interaction of government bodies and civil society, free access to information by citizens, increasing the efficiency of government bodies, and creating conditions in which citizens can take part in management processes implementing the principles of public administration.

In a modern economy, advanced information technology transforms data into a specific form of capital. Thus, the economic benefits of transforming public administration using technologies for the electronification of services contribute to an increase in the efficiency of interaction between the subjects of the economic and social environment (Miśkiewicz, 2018). The key goals of the transformation of public administration in this direction are to ensure the achievement of the following goals:

1. Obtaining the most complete and objective data in real-time.

2. The ability to automate the analysis of large amounts of data in the shortest possible time.

3. Acceleration of the mode of development of management decisions using a comprehensive analysis of the initial information data. 
4. Orientation of official management structures to the needs and interests of the user's society, taking into account the specifics of various situations and the specifics of regional conditions.

A comprehensive procedure for the digitalization of the public administration sphere is presented in Fig. 4.

Fig. 4. Transformation of public administration using innovative digitalization technologies

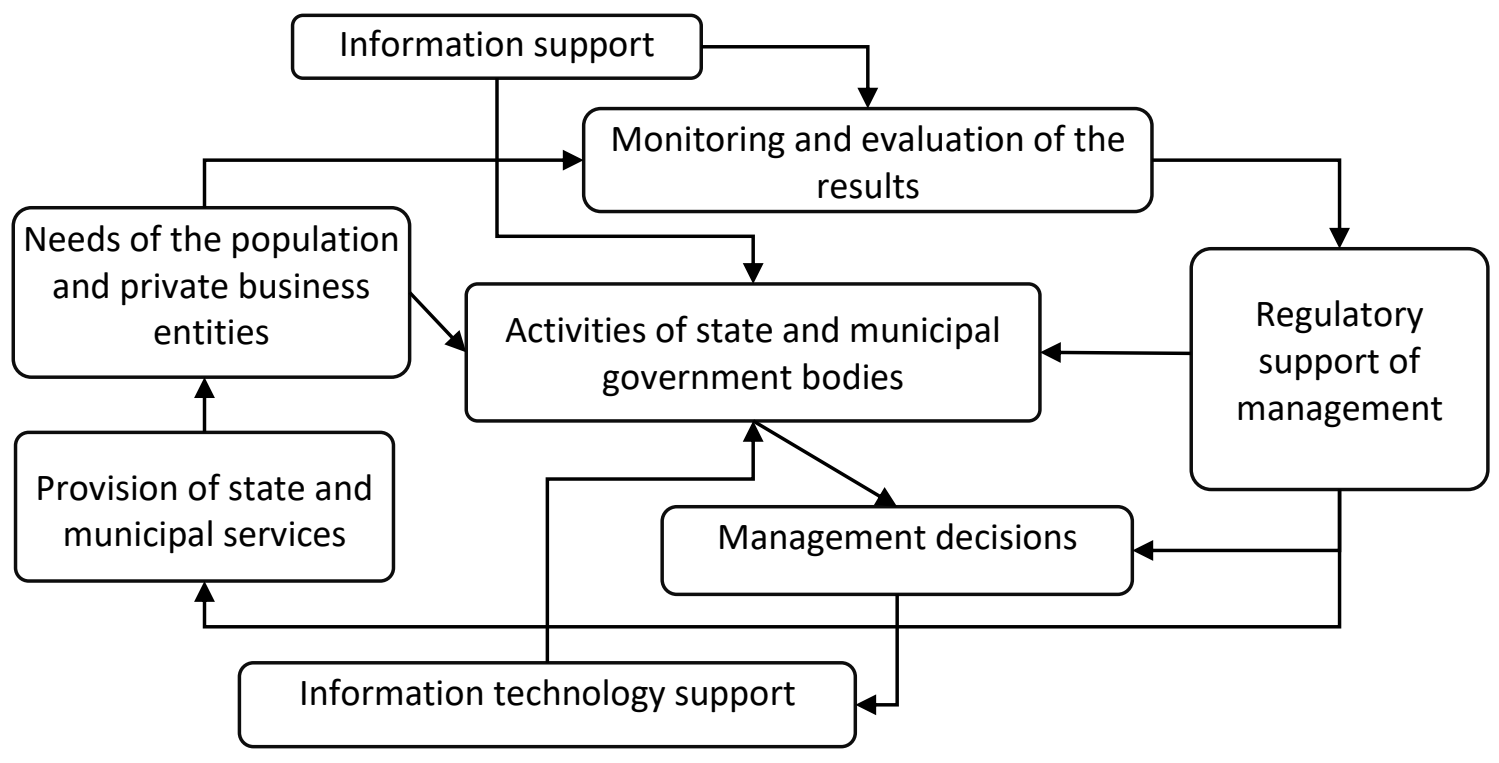

It should be noted that the reason for the need to transform public administration into public is the problem of ineffective distribution of state powers and the lack of interconnection between the assigned functions and the material, human and financial resources allocated to the authorities. The control and analysis capabilities of the distribution and consumption of these resources, in the context of an expanded state bureaucratic apparatus, are very scarce; this gives rise to corruption tendencies and further exacerbates the problem of excessive and ineffective budget spending. Simultaneously, although digitalization does not solve the problem of corruption and inefficiency, it makes it possible to improve the quality of control and analysis of the costly parts of both state and local budgets (Addo, 2021). The capabilities of information technologies used for the purpose of innovative changes in public administration are capable of delegating part of the state control functions to society and non-profit organizations, which will increase both the transparency of spending and the degree of population involvement in management processes.

An example of such transformations with the use of digitalization is the creation of an information state portal, among the advantages of which are:

- improving the self-organization of citizens;

- effective application of e-democracy tools;

- optimally structured electronic control process

- a system for the provision of administrative services;

- effective use of information technology;

- interaction of citizens with government and business;

- involvement of citizens in public administration processes and

- the processes of making government decisions (Korauš et al., 2019).

The formation of a transformation mechanism through the digitalization of public administration should be carried out both in the form of a key direction of the state's economic policy and a sociopolitical course of action that ensures the active participation of various public administration structures at all levels. 


\section{Experiment and analysis of results.}

The basis for the experimental part of testing the theory about the transformation of public administration through innovative technologies of its digitalization will be the analysis of the policy of the concept for the development of e-government in Ukraine. This public administration transformation policy was developed in 2016 and focused on three key areas:

- modernization of the public services sector;

- transformation of public administration;

- development of electronic government;

The comprehensive action plan covers all spheres of socio-economic relations and is aimed at a radical restructuring and transformation of the entire public administration system. The result of this program's implementation is considered to be the transition to a fully democratic form of public administration built with the use of deep integration of information technologies in all spheres of modern society.

The program's priority task and its first step was the implementation of a unified state portal for the provision of electronic services, the introduction of electronic contracts, and the promotion of digital communications between government departments. An important milestone in the transformation of public administration was the use of innovative means of electronic identification of a person, which was a barrier to applying public administration digitalization methods. As part of the agreement on the introduction of a visa-free regime with the European Union, since 2015, Ukraine has introduced a biometric passport of a citizen to travel abroad. In addition, since 2016 in Ukraine, an internal biometric passport containing a contactless electronic medium in the form of a plastic ID card has been defined and introduced into use at the legislative level.

The main feature of biometric passports is a built-in electronic chip containing information about the document owner. In particular, in addition to standard data about a person (name, surname, place of registration, etc.), biometric parameters of the photo, a digitized signature, as well as digitized fingerprints will be entered into the electronic carrier. A graph showing the volume of issuance of new identity documents is shown in Fig. 5.

Fig. 5. Volumes of ID passports issued to citizens of Ukraine, thousand pieces

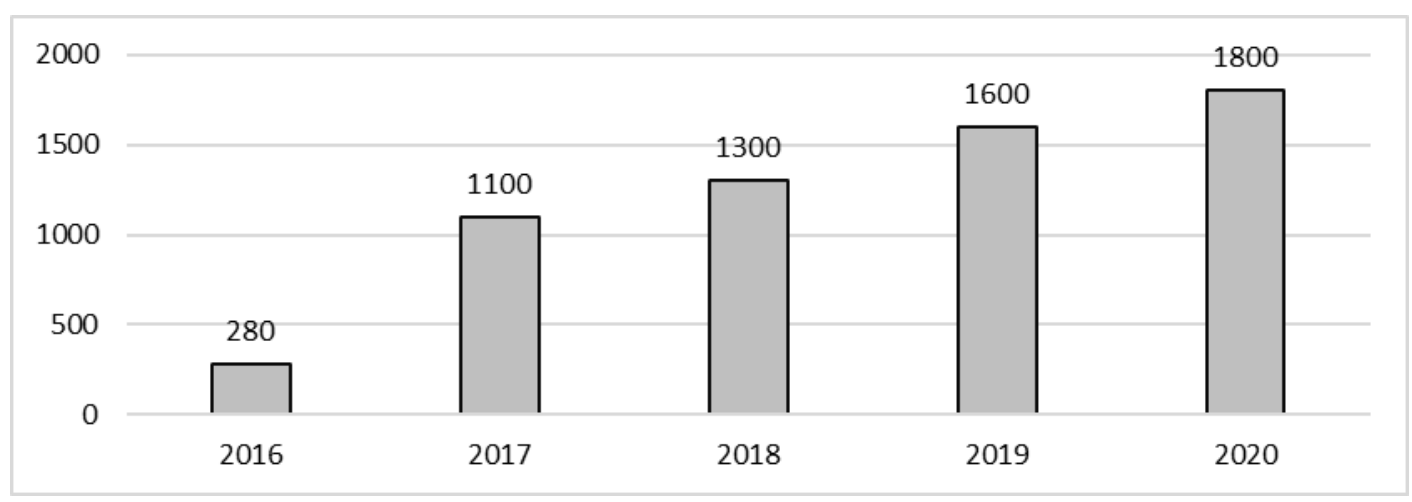

The introduction of new electronic documents made it possible to increase the efficiency of electronic identification of a person and make the provision of electronic services available and implement innovative forms of electronic interaction.

The following milestones can track the progress of the transformation of public administration:

The first stage - 2016-2017:

- optimization of the procedures for the provision of priority services;

- implementation of pilot projects to introduce the provision of priority services in electronic form and alternative methods of electronic identification and authentication. 
Second stage - 2018-2019:

- optimization of procedures for the provision of administrative services;

- introduction of priority services in electronic form.

The third stage - 2020-2021:

Ensure the provision of e-services in all spheres of public life, the provision of integrated eservices, as well as the introduction of cross-border e-services.

The processes of innovative transformation are not possible without organizational and administrative changes associated with the very process of providing the population with essential administrative services. Therefore, along with the creation of electronic portals, a policy was carried out to transfer administrative services to the people, from separate departmental offices to the socalled integrated service delivery centres.

The key task of integrated centres (or offices) of services is to quickly and comfortably provide the subject with the necessary administrative services. In contrast, the office functioning model involves accepting applications and providing basic consultations for priority administrative services.

Priority administrative services that have shifted from departmental to integrated offices include:

- registration of acts of civil status;

- registration of place of residence and issuance of passport documents;

- registration of ownership rights to real estate, in particular to land;

- registration of business entities;

- registration of vehicles and issuance of driver's licenses;

- social and administrative services.

The scheme of work of such an office assumes that the appeal's subject provides an application and a minimum list of necessary documents, and after the period established by law, he receives the necessary result for his appeal. The processes of creating such offices began in 2016, and they began to operate fully functional from 2017-2018. To control the level of user satisfaction, a survey was conducted in all three types of offices receiving administrative services, the results of which are presented in Fig. 6.

Fig.6 User satisfaction survey data for public service offices

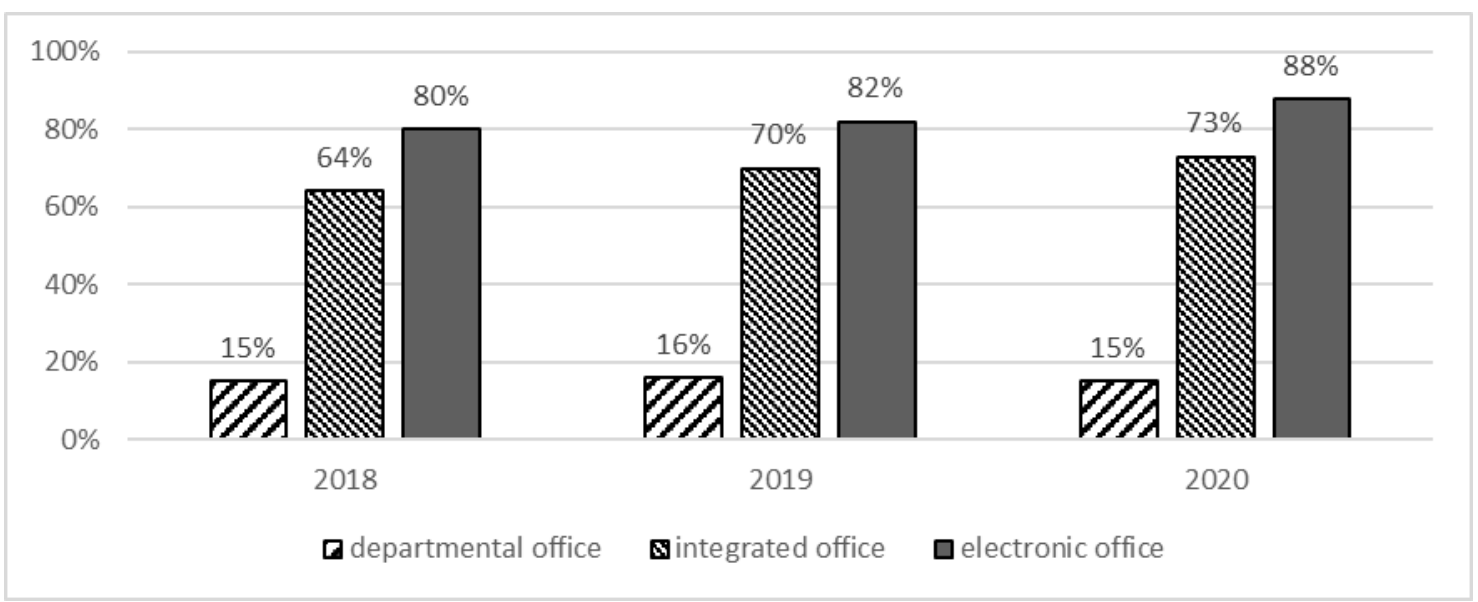

The graph shows a positive trend in the quality of the process of providing administrative services only in the integrated and electronic office, where the satisfaction rates increased from $64 \%$ and $80 \%$ to $73 \%$ and $88 \%$, respectively. It should be noted that according to the survey, users of electronic offices initially perceived the fact of the possibility of remote access to administrative services positively. Simultaneously, the level of assessment of departmental offices' work remained 
unchanged at the deficient level of $15 \%$, indicating an excessive bureaucratization of the main processes.

The transformation of public administration, in the context of economic and political changes in Ukraine, among other things, sets as its goals a number of essential tasks in our opinion:

- improving the quality of the provision of administrative services for citizens and business entities;

- improving the efficiency of government and local government bodies;

- ensuring the mobility of citizens and business entities in modern economic conditions;

- reducing the risk of corruption in the provision of administrative services;

- improving the business climate and increasing the investment attractiveness of the state.

It is worth noting that over the past five years, since the first steps to transform public administration, society and the government of Ukraine have passed a complicated and thorny path; nevertheless, the state is confidently pursuing its policy and achieving results on the path of increasing digitalization and transformation of public administration.

\section{Conclusion.}

Modern economic and political realities dictate the need for analysis and practical application of various tools and technologies for transforming the public administration system. Digital transformation, the introduction of electronic administrative services, the development of the concept of e-government are important tools for transforming both societies in general and the public administration sector in particular. Without a systemic transformation of management processes, without a radical restructuring of the entire state administration apparatus's work, it isn't easy to obtain adequate results from these processes.

The complexity of the public administration system itself, the complex nature of interaction and the long-term effects of the impact of transformation technologies require a cautious approach to the choice of tools with which they will carry out. Achieving the goals of public administration is impossible without the mobilization, organization, and coordination of human resources, without both the state and the private sector's efforts. It should be borne in mind that the mentality of perception of digitalization processes for business entities is the key to strengthening competitive advantages; simultaneously, for government authorities, the perception of these processes as positive does not seem so obvious. The crucial role of society's impact on the transformation processes allowed Ukraine to launch a comprehensive public administration system.

\section{References}

1. Addo, A. (2021). Controlling petty corruption in public administrations of developing countries through digitalization: An opportunity theory informed study of Ghana customs. Information Society, 37(2), pp. 99-114.

2. Adejare, A., Olla, J., \& Oluwafemi, J. (2014). Towards A Theoretical Definition of Public Administration. IOSR Journal of Business and Management, 16(3), pp. 65-70. DOI: 10.9790/487X16356570

3. Andriyash, V., \& Yevtushenko, A. (2018). Concept of public administration in the domestic scientific discussion. Public Administration and Regional Development. 2018(1), pp. 50-64. DOI: 10.26693/pard2018.01.01

4. Baklanova, O., Petrova, M., \& Koval, V. (2020). Institutional transmission in economic development. Ikonomicheski Izsledvania, 29(1), pp. 68-91.

5. Buha, H. (2021). Concept of public expertise and its significance in the activities of public administration bodies. DOI: 10.32366/2523-4269-2021-74-1-64-69 
6. Chernykh, S. (2020). Modern concepts of public administration and institutional risks. Society and economy. DOI: 10.31857/S020736760010114-4

7. Hidirova, B. (2020). The fundamental significance of information technology in modern economic growth and development. Conference: Specialized and multidisciplinary scientific researches. DOI: 10.36074/11.12.2020.v1.10

8. Korauš, A., Dobrovič, J., Polák, J., \& Backa, S. (2019). Aspects of the security use of payment card pin code analyzed by the methods of multidimensional statistics. Entrepreneurship and Sustainability Issues, 6(4), pp. 2017-2036.

9. Kuzmenko, H., Tsvirko, O., Sedikova, I., Khymych, O., Tarasenko, O., \& Doroshenko, O. (2019). The experimental model of procurement in public administration. International Journal of Innovative Technology and Exploring Engineering, 8(11), pp. 2773-2778.

10. Kwilinski, A., Volynets, R., Berdnik, I., Holovko, M., \& Berzin, P. (2019). E-Commerce: Concept and Legal Regulation in Modern Economic Conditions. Journal of Legal, Ethical and Regulatory Issues, 22(SI2), 1544-0044-22-SI-2-357: 1-6. Retrieved from https://www.abacademies.org/articles/ECommerce-concept-and-legal-regulation-in-modern-economic-conditions-1544-0044-22-SI-2357.pdf

11.Miśkiewicz, R. (2018). The Importance of Knowledge Transfer on the Energy Market. Polityka Energetyczna, 21(2), 49-62. http://dx.doi.org/10.24425\%2F122774

12. Petrenko, P. (2011). Modernization of ukrainian economy and state administration. Actual Problems of Economics, 123(9), pp. 22-32.

13. Razumei, H., \& Razumei, M. (2020). Digitalization of public administration as a component of digital transformation of Ukraine. DOI: 10.32836/2310-9653-2020-2.25

14.Shavkun, I., \& Dybchynska, Ya. (2017). New public management as a concept of public administration. Humanities Bulletin of Zaporizhzhe State Engineering Academy. DOI: 10.30839/2072-7941.2017.102146

15.Thapa, I. (2020). Public Administration: Meaning, Scope and Its Nature. DOI: 10.13140/RG.2.2.33704.80641

16. WerehIst, A., \& Istislam, I. (2018). Conflict in Management of Passive State Administrative Decision in State Administrative Dispute. Brawijaya Law Journal, 5(2), pp. 249-260. DOI: 10.21776/ub.blj.2018.005.02.08 